\title{
Realistic Rescue Simulation Method with Consideration of Road Network Restrictions
}

\author{
Kohei Arai 1 \\ Graduate School of Science and Engineering \\ Saga University \\ Saga City, Japan
}

\author{
Takashi Eguchi ${ }^{1}$ \\ Graduate School of Science and Engineering \\ Saga University \\ Saga City, Japan
}

\begin{abstract}
A realistic rescue simulation method with consideration of road network restrictions is proposed. Decision making and emergency communication system play important roles in rescue process when emergency situations happen. The rescue process will be more effective if we have appropriate decision making method and accessible emergency communication system. In this paper, we propose centralized rescue model for people with disabilities. The decision making method to decide which volunteers should help which disabled persons is proposed by utilizing the auction mechanism. The GIS data are used to present the objects in a large-scale disaster simulation environment such as roads, buildings, and humans. The Gama simulation platform is used to test our proposed rescue simulation model. There are road network restrictions, road disconnections, one way traffic, roads which do not allow $U$ Turn, etc. These road network restrictions are taken into account in the proposed rescue simulation model. The experimental results show around $10 \%$ of additional time is required for evacuation of victims.
\end{abstract}

Keywords-Rescue Simulation for people with disabilities; GIS MultiAgent-based Rescue Simulation; Auction based Decision Making

\section{INTRODUCTION}

In an emergency situation, a human tends to perform two main activities: the rescue and the evacuation. It is very difficult and costly if we want to do experiments on human rescue and or evacuation behaviors physically in real scale level. It is found that multi agent-based simulation makes it possible to simulate the human activities in rescue and evacuation process [1, 2]. A multi agent-based model is composed of individual units, situated in an explicit space, and provided with their own attributes and rules [3]. This model is particularly suitable for modeling human behaviors, as human characteristics can be presented as agent behaviors. Therefore, the multi agent-based model is widely used for rescue and evacuation simulation [1-5].

In this study, GIS map is used to model objects such as road, building, human, fire with various properties to describe the objects condition. With the help of GIS data, it enables the disaster space to be closer to a real situation [5-10]. Kisko et al. (1998) employs a flow based model to simulate the physical environment as a network of nodes. The physical structures, such as rooms, stairs, lobbies, and hallways are represented as nodes which are connected to comprise a evacuation space. This approach allows viewing the movement of evacuees as a continuous flow, not as an aggregate of persons varying in physical abilities, individual dispositions and direction of movement [11]. Gregor et al. (2008) presents a large scale microscopic evacuation simulation. Each evacuee is modeled as an individual agent that optimizes its personal evacuation route. The objective is a Nash equilibrium, where every agent attempts to find a route that is optimal for the agent [12]. Fahy (1996; 1999) proposes an agent based model for evacuation simulation. This model allows taking in account the social interaction and emergent group response. The travel time is a function of density and speed within a constructed network of nodes and arcs [13, 14]. Gobelbecker et al. (2009) presents a method to acquire GIS data to design a large scale disaster simulation environment. The GIS data is retrieved from a public source through the website OpenStreetMap.org. The data is then converted to the Robocup Rescue Simulation system format, enabling a simulation on a real world scenario [15]. Sato et al. (2011) also proposed a method to create realistic maps using the open GIS data. The experiment shows the differences between two types of maps: the map generated from the program and the map created from the real data [2]. Ren et al. (2009) presents an agent-based modeling and simulation using Repast software to construct crowd evacuation for emergency response for an area under a fire. Characteristics of the people are modeled and tested by iterative simulation. The simulation results demonstrate the effect of various parameters of agents [3]. Cole (2005) studied on GIS agent-based technology for emergency simulation. This research discusses about the simulation of crowding, panic and disaster management [6]. Quang et al. (2009) proposes the approach of multi-agent-based simulation based on participatory design and interactive learning with experts' preferences for rescue simulation [9]. Hunsberger et al. (2000), Beatriz et al. (2003) and Chan et al. (2005) apply the auction mechanism to solve the task allocation problem in rescue decision making. Christensen et al. (2008) presents the BUMMPEE model, an agent-based simulation capable of simulating a heterogeneous population according to variation in individual criteria. This method allows simulating the behaviors of people with disabilities in emergency situation [23].

Our study will focus mainly on proposing a rescue model for people with disabilities in large scale environment. This rescue model provides some specific functions to help disabled people effectively when emergency situation occurs. Important components of an evacuation plan are the ability to receive critical information about an emergency, how to respond to an emergency, and where to go to receive assistance. We propose 
a wearable device which is attached to body of disabled people. This device measures the condition of the disabled persons such as their heart rate, body temperature and attitude; the device can also be used to trace the location of the disabled persons by GPS. That information will be sent to emergency center automatically. The emergency center will then collect that information together with information from volunteers to assign which volunteer should help which disabled persons.

The rest of the paper is organized as follows. Section 2 describes the centralized rescue model and the rescue decision making method. Section 3 provides the experimental results of different evacuation scenarios. Finally, section 4 summarizes the work of this paper.

\section{PROPOSED RESCUE SYSTEM}

\section{A. Proposed Rescue Model}

Important components of an evacuation plan are the ability to receive critical information about an emergency, how to respond to an emergency, and where to go to receive assistance. We proposes a wearable device which is attached to body of disabled people. This device measures the condition of the disabled persons such as their heart rate, body temperature and attitude; the device can also be used to trace the location of the disabled persons by GPS. Those information will be sent to emergency center automatically. The emergency center will then collect those information together with information from volunteers to assign which volunteer should help which disabled persons. The centralized rescue model presented has three types of agents: volunteers, disabled people and route network. The route network is also considered as an agent because the condition of traffic in a certain route can be changed when a disaster occurs. The general rescue model is shown in Figure 1.

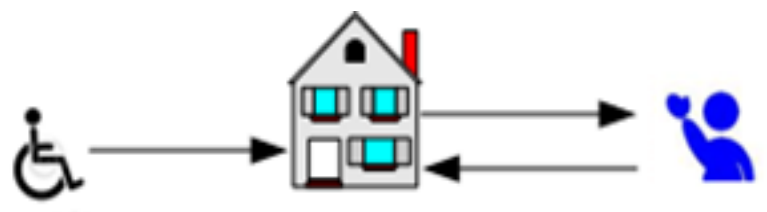

Fig. 1. Centralized Rescue Model

Before starting the simulation, every agent has to be connected to the emergency center in order to send and receive information. The types of data exchanged between agents and emergency center are listed as below.

\section{Message from agent}

A1: To request for connection to the emergency center

A2: To acknowledge the connection

A3: Inform the movement to another position

A4: Inform the rescue action for victim

A5: Inform the load action for victim

A6: Inform the unload action for victim

A7: Inform the inactive status

Message from emergency center

K1: To confirm the success of the connection

$\mathrm{K} 2$ : To confirm the failure of the connection

K3: To send decisive information
Before starting the simulation, every agent will send the command A1 to request for connection to the emergency center. The emergency center will return the response with a command $\mathrm{K} 1$ or $\mathrm{K} 2$ corresponding to the success or failure of their connection respectively. If the connection is established, the agent will send the command $\mathrm{A} 2$ to acknowledge the connection. The initial process of simulation is shown in Figure 2.

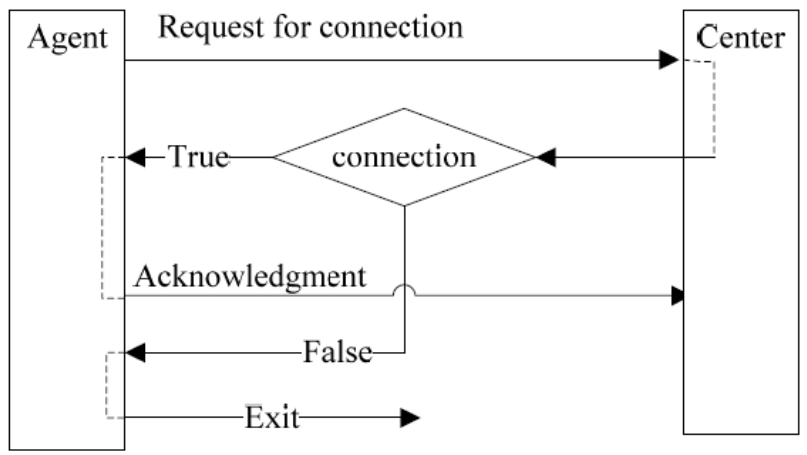

Fig. 2. Initial Process

After the initial process, all the connected agents will receive the decisive information such as the location of agents and health level via command $\mathrm{K} 3$; after that the rescue agents will make a decision of action and submit to the center using one of the commands from A3 to A7. At every cycle in the simulation, each rescue agent receives a command $\mathrm{K} 3$ as its own decisive information from the center, and then submits back an action command. The status of disaster space is sent to the viewer for visualization of simulation. The repeating steps of simulation are shown in Figure 3.

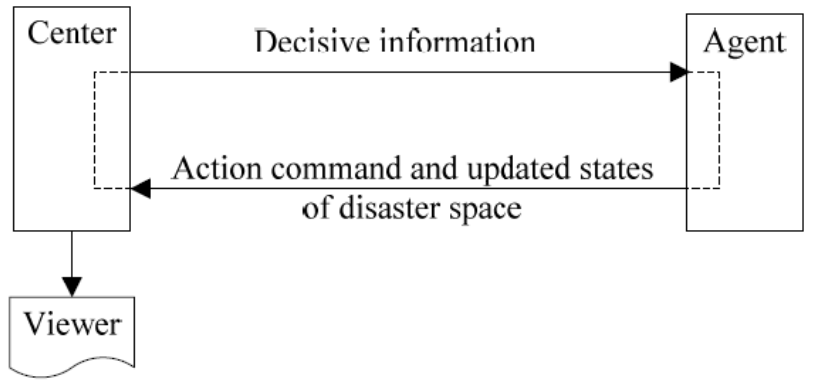

Fig. 3. Simulation Cycles

\section{B. Disaster Area Model}

The disaster area is modeled as a collection of objects: Nodes, Buildings, Roads, and Humans. Each object has properties such as its positions, shape and is identified by a unique ID. Table 1 to Table 7 presents the properties of Nodes,

Buildings, Roads and Humans object respectively. These properties are derived from RoboCup rescue platform with some modifications.

The topographical relations of objects are illustrated from Figure 4 to Figure 7 . The representative point is assigned to every object, and the distance between two objects is calculated from their representative points. 
TABLE I. PROPERTIES OF NODE OBJECT

\begin{tabular}{|c|c|c|}
\hline Property & Unit & Description \\
\hline $\mathrm{x}, \mathrm{y}$ & - & $\mathrm{x}-\mathrm{yC}$ Cordinate \\
\hline Edges & ID & Connected_road_and_Building \\
\hline
\end{tabular}

TABLE II. PROPERTIES OF BUILDING OBJECT

\begin{tabular}{|c|c|}
\hline Property & Description \\
\hline $\mathrm{x}, \mathrm{y}$ & $\begin{array}{c}\mathrm{x}-\mathrm{y} \text { coordinate of the representative } \\
\text { point }\end{array}$ \\
\hline Entrance & Node_connecting_building_and_road \\
\hline
\end{tabular}

TABLE III. PROPERTIES OF ROAD OBJECT

\begin{tabular}{|c|c|c|}
\hline Property & Unit & Description \\
\hline Start_Point_and_End_Point & ID & Point_to_enter_the_Road_ \\
\hline Length_and_Width & $\mathrm{m}$ & Length_and_width_of_Road \\
\hline Lane & Lane & Number_of_lanes \\
\hline Blocked_road & Lane & Number_of_blocked_lanes \\
\hline Clear_Cost & Cycle & Cost_required_for_clearing_blocks \\
\hline
\end{tabular}

TABLE IV. Properties OF VICTIM Agent

\begin{tabular}{|c|c|c|}
\hline Property & Unit & Description \\
\hline Position & ID & Object_where_victim_is_on \\
\hline $\begin{array}{c}\text { Position_in } \\
\text { road }\end{array}$ & $\mathrm{m}$ & $\begin{array}{c}\text { Lecgth_from_Start_Point_when_victim_is_on_ro } \\
\text { ad,_Otherwise_it_is_zero }\end{array}$ \\
\hline $\begin{array}{c}\text { Health_Le } \\
\text { vel }\end{array}$ & $\begin{array}{c}\text { Health_P } \\
\text { oint }\end{array}$ & Health_level_of_victim \\
\hline $\begin{array}{c}\text { Damage_P } \\
\text { oint }\end{array}$ & $\begin{array}{c}\text { Health_P } \\
\text { oint }\end{array}$ & Health_level_dwindles_by_Damage \\
\hline $\begin{array}{c}\text { Disability_ } \\
\text { Type }\end{array}$ & $\begin{array}{c}\text { Type(1- } \\
7)\end{array}$ & Disability_types \\
\hline $\begin{array}{c}\text { Disability_ } \\
\text { Level }\end{array}$ & $\begin{array}{c}\text { High_or } \\
\text { _Low }\end{array}$ & High_disability_level_means_Highest_Damage_P \\
oint
\end{tabular}

TABLE V. Properties of VolunteEr Agent

\begin{tabular}{|c|c|c|}
\hline Property & Unit & Description \\
\hline Position_on_road & ID & Object=that_victim_is_on \\
\hline Position_on_road & $\mathrm{m}$ & Length_from_Start_Point \\
\hline Current_Action & Type(1-3) & See_in_Table_VII \\
\hline Energy & Level(1-5) & Empty_level_of_vehicle_gasoline \\
\hline Panic_Level & Level(0-9) & Hesitance_level_of_decision \\
\hline
\end{tabular}

TABLE VI. ACTION OF VOLUNTEER AGENT

\begin{tabular}{|c|c|c|}
\hline Action_ID & Action & Description \\
\hline 1 & Stationary & Rescue_person_Stays \\
\hline 2 & Move_to_Victim & Rescue_person_moves_to_victim \\
\hline 3 & Move_to_Shelter & Rescue_person_carry_victim_to_shelter \\
\hline
\end{tabular}

TABLE VII. TYPE OF DISABILITY

\begin{tabular}{|c|c|}
\hline Type & Description \\
\hline 1 & Cognitive_Impaiment \\
\hline 2 & Dexterity_Impairment \\
\hline 3 & Mobility_Impairment \\
\hline 4 & Elderly \\
\hline 5 & Hearing_Impairment \\
\hline 6 & Speech_and_Language_Impairment \\
\hline 7 & Visdual_Impairment \\
\hline
\end{tabular}

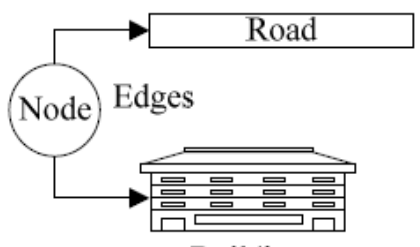

Building

Fig. 4. Node object

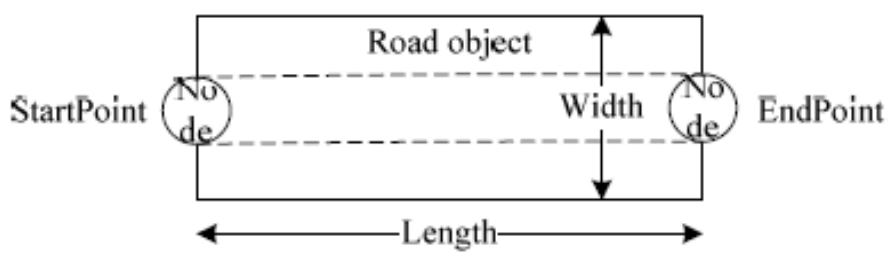

Fig. 5. Road object

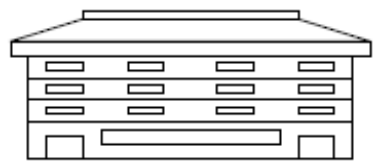

\section{Building object}

Fig. 6. Building object

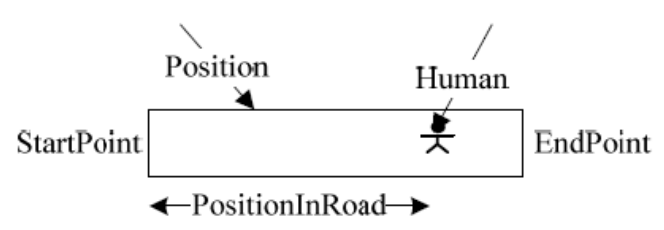

Fig. 7. Human object

\section{Path finding in Gama Simulation Platform}

After a volunteer makes the decision to help a certain victim, the path finding algorithm is used to find the route from volunteer agent to victim agent. The GIS data presents roads as a line network in graph type. Figure 8 shows an example of graph computation. The Dijkstra algorithm is implemented for the shortest path computation [8].

In this section, we present experimental studies on different scenarios. We show the experimental results with traditional rescue model which not considering the updated information of victims and volunteers such as health conditions, locations, traffic conditions.

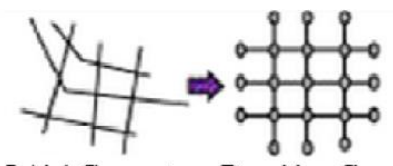

Initial Geometry Resulting Graph

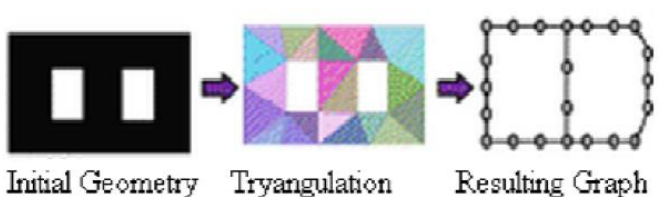

Fig. 8. Example of Graph Computation [8] 
The traditional rescue model provides fixed mission for which volunteers should help which victims. Whereas, our rescue model provides flexible mission for which volunteers should help which victims. The targets of volunteers can be changed dynamically according to current situation. The experimental results of our proposed rescue model are also presented to show the advantages comparing to traditional model.

The evacuation time is evaluated from the time at which the first volunteer started moving till the time at which all saved victims arrive at the shelters. The simulation model is tested using the Gama simulation platform $[8,10]$.

We consider the number of volunteers, number of disabled persons, panic level of volunteer, disability level of victim and the complexity of traffic as parameters to examine the correlation between these parameters with rescue time. The traffic complexity is function of the number of nodes and links in a road network.

Figure 9 presents the sample GIS map consisting of 4 layers: road, volunteer, disabled person and shelter. The initial health levels of disabled persons are generated randomly between 100 point and 500 point. If the health level is equal or less than zero, the corresponding agent is considered as dead.

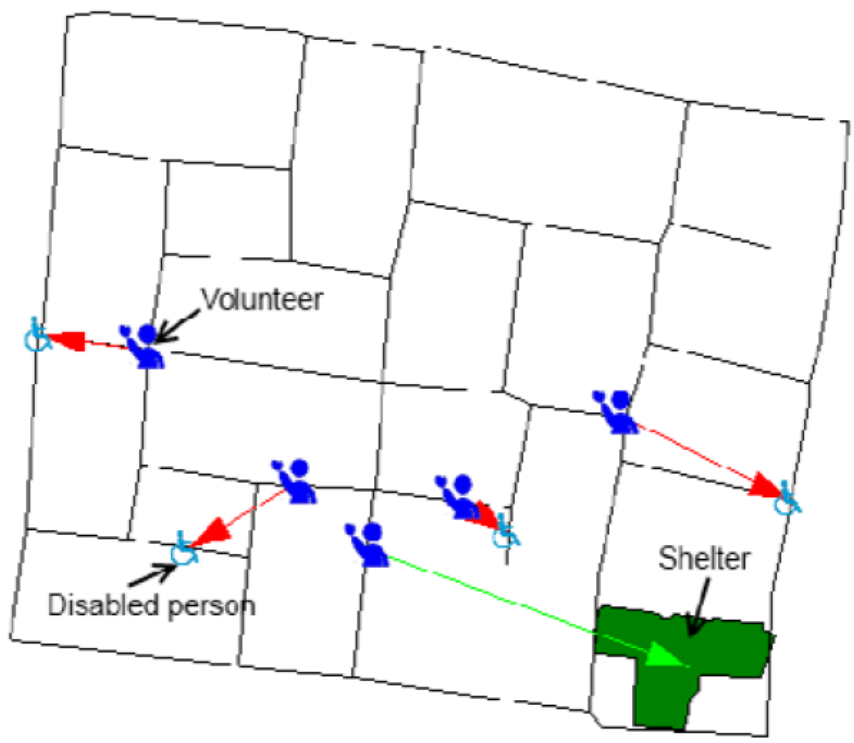

Fig. 9. Sample GIS Map of Disaster Space

\section{Realistic Simulation Designating to Saga City, Japan}

Figure 10 (a) shows the rescue simulation site which is situated at Saga University and the surrounding areas. The shelter around this site is Saga University. Meanwhile, Figure 10 (b) shows road network and locations of victims and rescue peoples as initial conditions. At the top right corner, entrance gate is situated at the shelter.

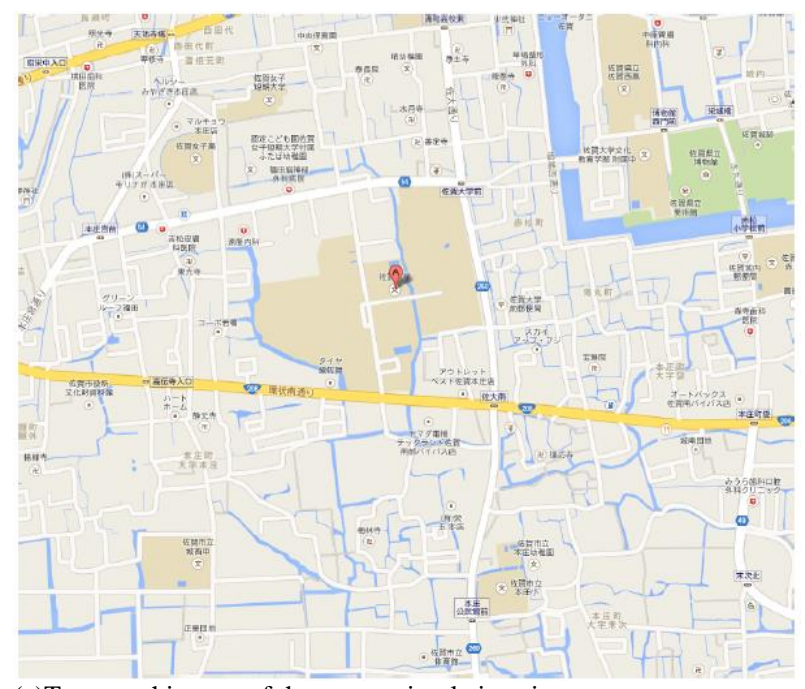

(a)Topographic map of the rescue simulation site

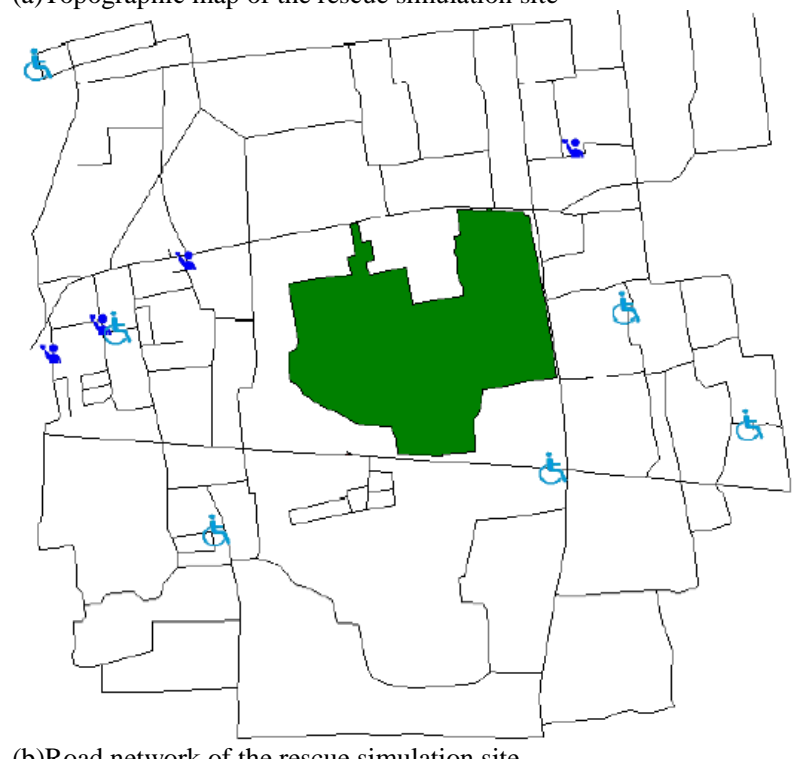

(b) Road network of the rescue simulation site

Fig. 10. Rescue simulation site of Saga University and its surrounding areas

\section{EXPERIMENTS}

Simulations are conducted with the aforementioned initial conditions on the road network. There are two victims. (1)The rescue person goes the victim \#1, firstly, and (2), (3) he goes to the victim \#2 after that. Then he goes to the shelter together with the victims \#1 and \#2. It is expected the rescue route length would be $4.34 \mathrm{~km}$ and the expected rescue time would be 10 min. and $40 \mathrm{sec}$. as shown in Figure 11 (a). Figure 11 (b) shows the route for rescue the victim \#3. In this case, the number of rescue victims is just one. Therefore, the route length is $2.66 \mathrm{~km}$ and it takes $5 \mathrm{~min}$. and $16 \mathrm{sec}$. Another possible route for rescue the victim \#4 is shown in Figure 11 (c). There is only one victim. Therefore, the route length is $2.36 \mathrm{~km}$ and the time required for rescue is $4 \mathrm{~min}$. and $18 \mathrm{sec}$. 


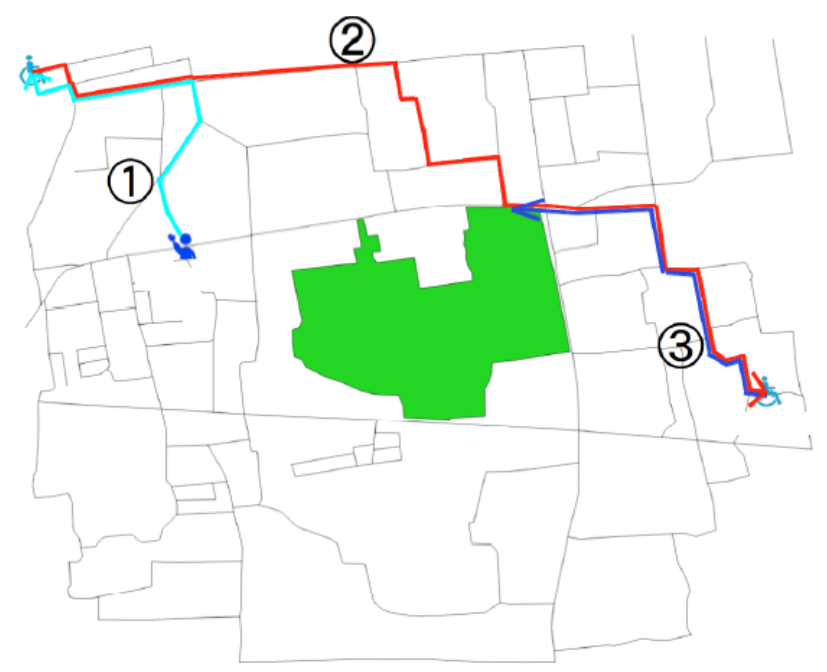

(a)Possible route for rescue the victims \#1 and \#2

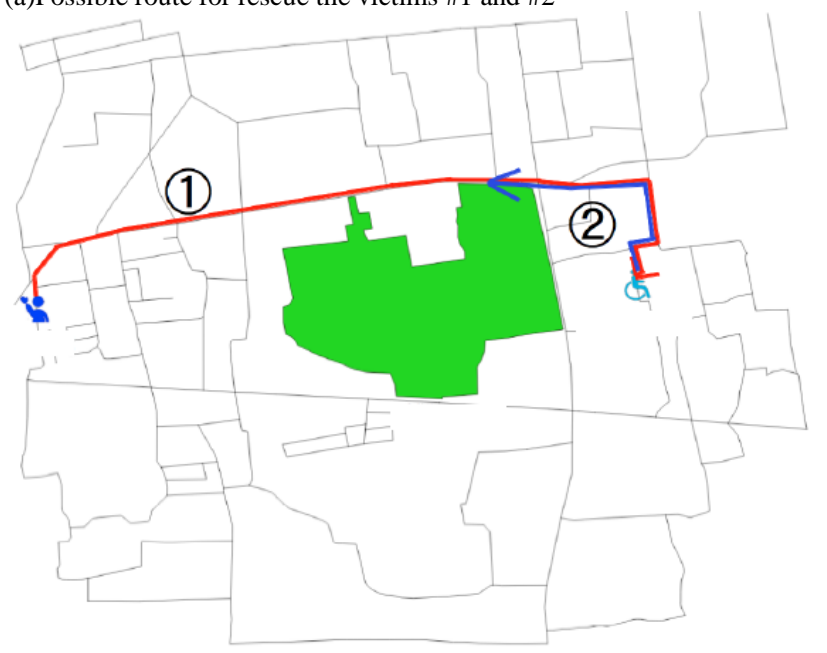

(b)Possible route for rescue the victim \#3

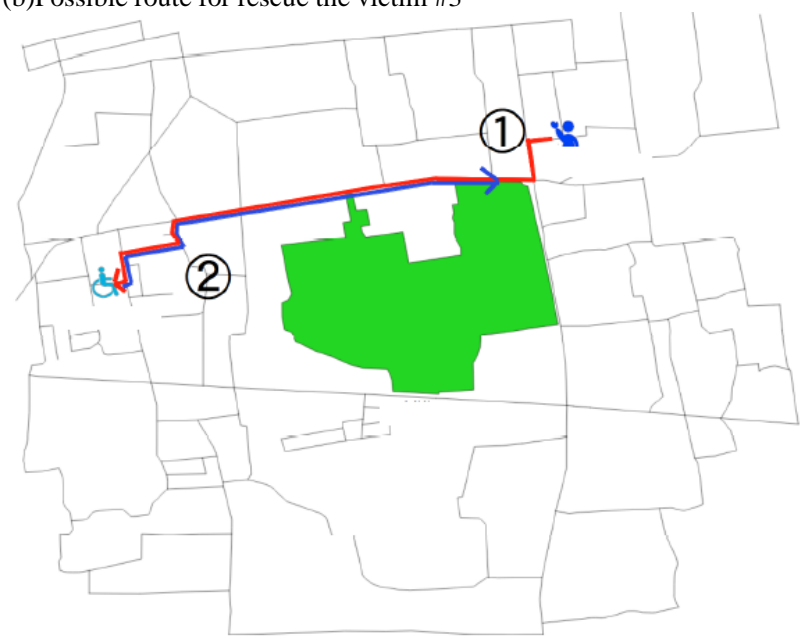

(c)Possible route for rescue the victim \#4

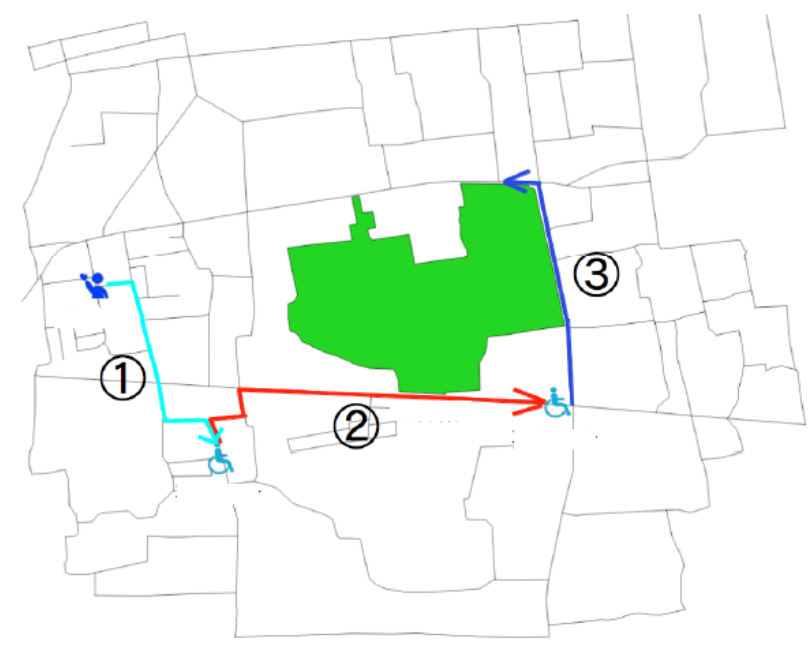

(d)Possible route for rescue the victims \#5 and \#6

Fig. 11. Possible routes for rescue the victims \#1-\#6

On the other hand, the possible route for rescue the victim \#5 and \#6 is shown in Figure 11 (d). In this case, the number of victims is two for the rescue person. The route length is 2.385 $\mathrm{km}$ and it takes $6 \mathrm{~min}$. and $20 \mathrm{sec}$. The time required for rescue for each case is summarized in Table 8. These are simulation results. The experiments are conducted in real world twice. The time required for rescue is shown in Table 9 (the first trial) and 10 (the second trial).

TABLE VIII. THE TIME REQUIRED FOR RESCUE (SimULATION)

\begin{tabular}{|c|c|c|c|c|}
\hline & Rescue A & Rescue B & Rescue C & Rescue D \\
\hline First victim & $2: 26$ & $3: 58$ & $2: 50$ & $2: 10$ \\
\hline Second victim & $8: 00$ & --- & --- & $4: 18$ \\
\hline Rescue time & $10: 40$ & $5: 16$ & $4: 18$ & $6: 20$ \\
\hline
\end{tabular}

TABLE IX. THE TIME REQUiRED FOR RESCUE (REAL WORLD TRIAL \#1)

\begin{tabular}{|c|c|c|c|c|}
\hline & Rescue A & Rescue B & Rescue C & Rescue D \\
\hline First victim & $2: 56$ & $5: 36$ & $3: 36$ & $2: 36$ \\
\hline Second victim & $11: 41$ & --- & --- & $6: 10$ \\
\hline Rescue time & $16: 54$ & $7: 47$ & $6: 37$ & $8: 37$ \\
\hline
\end{tabular}

TABLE X. THE Time ReQuiRED For RESCUE (REAL WORLD TRIAL \#2)

\begin{tabular}{|c|c|c|c|c|}
\hline & Rescue A & Rescue B & Rescue C & Rescue D \\
\hline First victim & $1: 45$ & $5: 54$ & $4: 12$ & $1: 49$ \\
\hline Second victim & $10: 22$ & --- & --- & $4: 51$ \\
\hline Rescue time & $14: 57$ & $8: 13$ & $6: 59$ & $7: 13$ \\
\hline
\end{tabular}

Most of the rescue simulation software does not care about the one way roads and the roads of which u-turn is impossible. There, however, are one way traffic roads and the u-turn impossible roads in the real world situation. Therefore, it takes much time for rescue when these realistic road conditions are taken into account in comparison to the simulations and the experiments which do not taken into account the conditions. 
Figure 12 (a) shows an example of the one way traffic road in Saga city. Black cross mark shows one way traffic road from right to left. Therefore, the rescue person cannot take this one way traffic road (Figure 12 (b)). On behalf of this road, the rescue person takes another alternative road (Second shortest pass shown in Figure 12(c)). On the other hand, there are narrow roads of which u-turn cannot be done as is shown in Figure 13. Figure 13 (a) shows the route for conventional rescue simulation result while Figure 13 (b) shows the route for the proposed rescue simulation. Due to the fact that the road is narrow which does not allow make any u-turn, the rescue person have to take the alternative route of Figure 13 (b). As the results of these considerations on the proposed rescue simulation, the rescue person $\mathrm{A}, \mathrm{B}, \mathrm{C}, \mathrm{D}$ takes the rescue time and the route length which are shown in Table 11. Meanwhile, Table 12 shows rescue time in the case of the considerations of one way traffic road and u-turn impossible road in the proposed rescue simulation. On the other hand, Table 13 shows effects of rescue time increasing in the case of the considerations of one way traffic road and u-turn impossible road in the proposed rescue simulation. In case of the consideration of one way traffic road and u-turn impossible road, the alternative route of the second shortest pass has to be taken. Therefore, rescue time is increased.

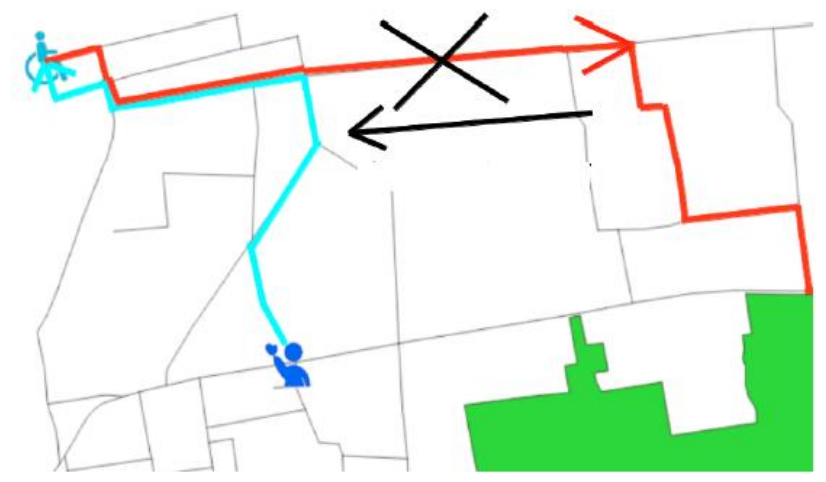

(a)One way traffic road

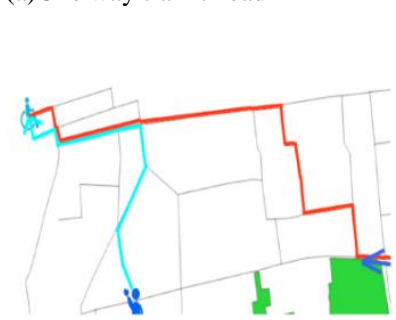

(b)Shortest pass

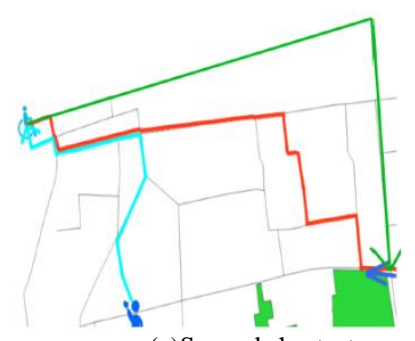

(c)Second shortest pass

Fig. 12. Consideration of one way traffic road in the proposed rescue simulation

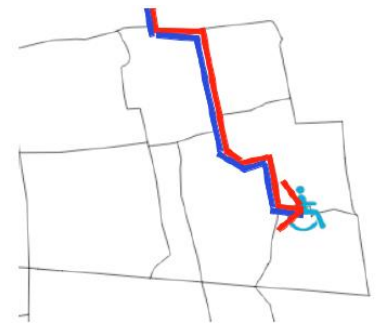

(a)U-turn traffic road

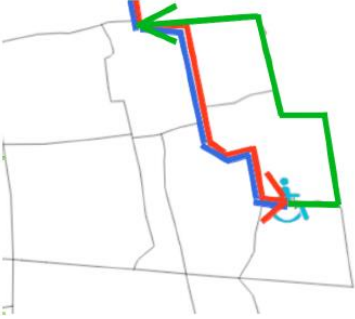

(b)Alternative route
Fig. 13. Consideration of U-turn impossible roads in the proposed rescue simulation-

TABLE XI. THE TIME REQUIRED FOR RESCUE AND THE ROUTE LENGTH

\begin{tabular}{|c|c|c|c|c|}
\hline & Rescue A & Rescue B & Rescue C & Rescue D \\
\hline Route length & 4.34 & 2.66 & 2.36 & 2.38 \\
\hline Rescue time & 2'26' & 3'58' & 2'50' & 2'10' \\
\hline
\end{tabular}

TABLE XII. RESCUE TIME IN THE CASE OF THE CONSIDERATIONS OF ONE WAY TRAFFIC ROAD AND U-TURN IMPOSSIBLE ROAD IN THE PROPOSED RESCUE SIMULATION

\begin{tabular}{|c|c|c|c|c|}
\hline & Rescue A & Rescue B & Rescue C & Rescue D \\
\hline First Victim & 2'35' & 4'10' & 3'40”' & 2.10 \\
\hline Second victim & 9'14' & --- & --- & 4'30' \\
\hline Overall Rescue time & $12^{\prime} 155^{\prime}$ & 5'44' & 6'1'” & 6'50' \\
\hline
\end{tabular}

TABLE XIII. EFFECT OF THE CONSIDERATIONS OF ONE WAY TRAFFIC ROAD AND U-TURN IMPOSSIBLE ROAD IN THE PROPOSED RESCUE SIMULATION

\begin{tabular}{|c|c|c|c|c|}
\hline & Rescue A & Rescue B & Rescue C & Rescue D \\
\hline First Victim & $+9 "$ & $+12 "$ & $+50 "$ & $0 "$ \\
\hline Second victim & $+1 ' 14$ '” & --- & --- & $+12 "$ \\
\hline Overall Rescue time & $+1 ' 35^{\prime \prime}$ & $+28^{\prime \prime}$ & $+1 ' 43^{\prime \prime}$ & $+30^{\prime \prime}$ \\
\hline
\end{tabular}

It is much hard to pass the route if the road is much narrow road which is shown in Figure 14. Figure 14 (a) shows the photo of the narrow road while Figure 14 (b) shows the narrow road on the topographic map.

In such case, it is better to take another alternative much wider road than the narrow road from the rescue time point of view. Therefore, it is better to take the route \#2 (Figure 15 (b)) rather than the route \#1 (Figure 15 (a)).

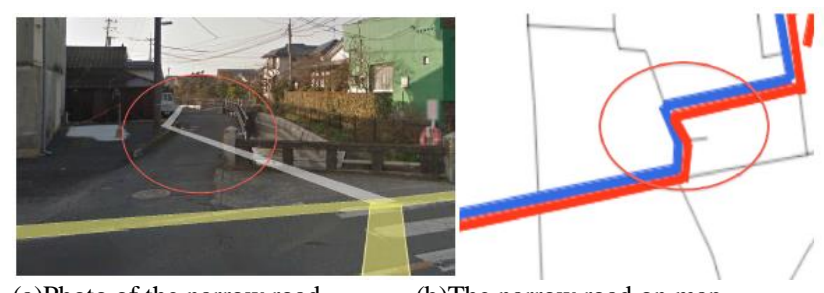

(a)Photo of the narrow road

(b)The narrow road on map

Fig. 14. Consideration of the narrow road in the proposed rescue simulation

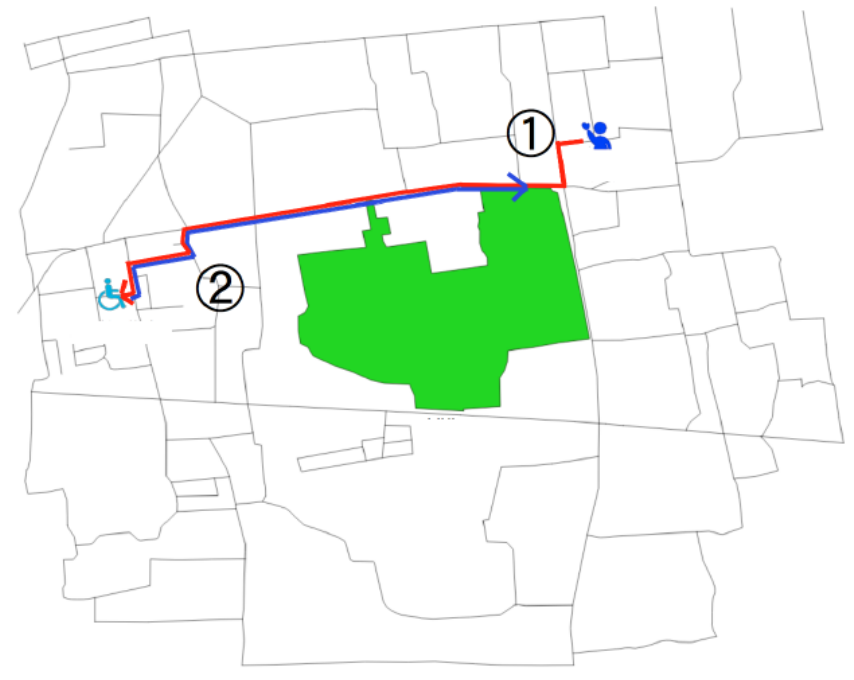

(a)Route \#1 


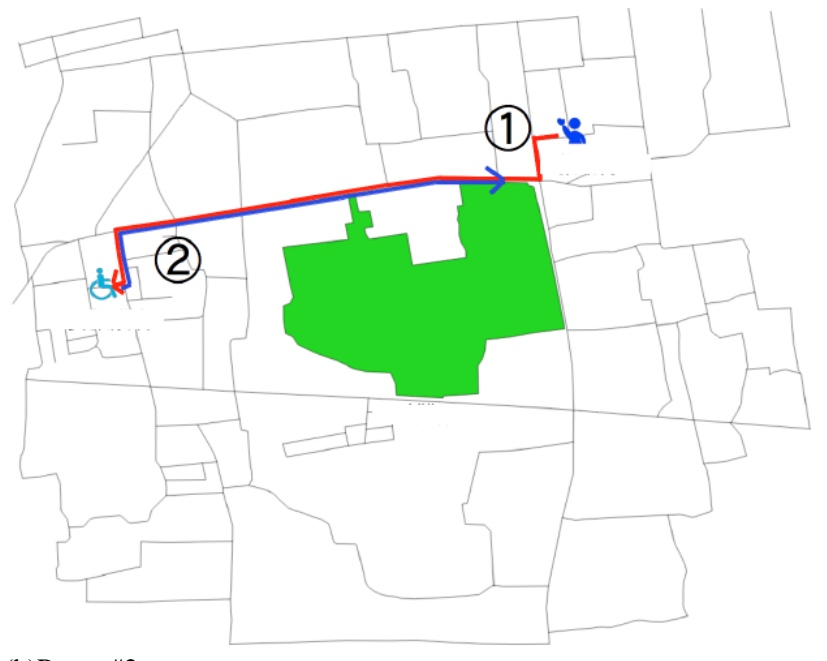

(b)Route \#2

Fig. 15. Consideration of priority of wide roads rather than narrow roads in the proposed rescue simulation

Meanwhile, there are the routes which take much longer time for crossing very wide boulevards than narrow roads as shown in Figure 16. Figure 16 (a) shows an example of photo of the route which takes much longer time for crossing very wide boulevard than narrow roads while Figure 16 (b) shows the route which takes much longer time for crossing very wide boulevard than narrow roads on map.

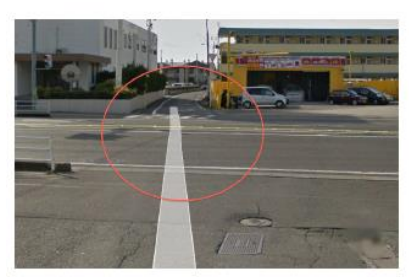

(a)Photo of the boulevard

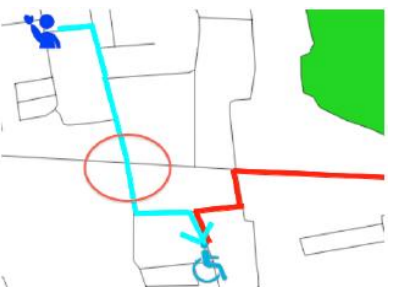

(b)The boulevard on map
Fig. 16. Routes which take much longer time for crossing very wide boulevards than narrow roads

\section{CONCLUSION}

A realistic rescue simulation method with consideration of road network restrictions is proposed. Decision making and emergency communication system play important roles in rescue process when emergency situations happen. The rescue process will be more effective if we have appropriate decision making method and accessible emergency communication system.

In this paper, we propose centralized rescue model for people with disabilities. The decision making method to decide which volunteers should help which disabled persons is proposed by utilizing the auction mechanism. The GIS data are used to present the objects in a large-scale disaster simulation environment such as roads, buildings, and humans.

The Gama simulation platform is used to test our proposed rescue simulation model. There are road network restrictions, road disconnections, one way traffic, roads which do not allow U-Turn, etc. These road network restrictions are taken into account in the proposed rescue simulation model.
The experimental results show around $10 \%$ of additional time is required for evacuation of victims in maximum. In order to reduce rescue time, considerations of priority of wide roads rather than narrow roads in the proposed rescue simulation are taking into account.

\section{REFERENCES}

[1] Obelbecker G., \& Dornhege M., "Realistic cities in simulated environments - an Open Street Map to Robocup Rescue converter", Online-Proceedings of the Fourth International Workshop on Synthetic Simulation and Robotics to Mitigate Earthquake Disaster, 2009.

[2] Sato, K., \& Takahashi, T., "A study of map data influence on disaster and rescue simulation's results", Computational Intelligence Series, vol. 325. Springer Berlin / Heidelberg, 389-402, 2011.

[3] Ren C., Yang C., \& Jin S., "Agent-Based Modeling and Simulation on emergency”, Complex 2009, Part II, LNICST 5, 1451 - 1461, 2009.

[4] Zaharia M. H., Leon F., Pal C., \& Pagu G., "Agent-Based Simulation of Crowd Evacuation Behavior", International Conference on Automatic Control, Modeling and Simulation, 529-533, 2011.

[5] Quang C. T., \& Drogoul A., "Agent-based simulation: definition, applications and perspectives", Invited Talk for the biannual Conference of the Faculty of Computer Science, Mathematics and Mechanics, 2008.

[6] Cole J. W., Sabel C. E., Blumenthal E., Finnis K., Dantas A., Barnard S., \& Johnston D. M., "GIS-based emergency and evacuation planning for volcanic hazards in New Zealand", Bulletin of the New Zealand society for earthquake engineering, vol. 38, no. 3, 2005.

[7] Batty M., "Agent-Based Technologies and GIS: simulating crowding, panic, and disaster management", Frontiers of geographic information technology, chapter 4, 81-101, 2005.

[8] Patrick T., \& Drogoul A., "From GIS Data to GIS Agents Modeling with the GAMA simulation platform", TF SIM 2010.

[9] Quang C. T., Drogoul A., \& Boucher A., "Interactive Learning of Independent Experts' Criteria for Rescue Simulations", Journal of Universal Computer Science, Vol. 15, No. 13, 2701-2725, 2009.

[10] Taillandier T., Vo D. A., Amouroux E., \& Drogoul A., "GAMA: a simulation platform that integrates geographical information data, agentbased modeling and multi-scale control", In Proceedings of Principles and practice of multi-agent systems, India, 2012.

[11] Kisko, T.M., Francis, R.L., Nobel C.R., "EVACNET4 User's Guide”, University of Florida, 1998.

[12] Gregor, Marcel R., \& Nagel K., "Large scale microscopic evacuation simulation", Pedestrian and Evacuation Dynamics, 547-553, 2008.

[13] Fahy R. F., “User's Manual, EXIT89 v 1.01, An Evacuation Model for High-Rise Buildings, National Fire Protection Association”, Quincy, Mass, 1999.

[14] Fahy R. F., "EXIT89 - High-Rise Evacuation Model -Recent Enhancements and Example Applications" Interflam '96, International Interflam Conference - 7th Proceedings; Cambridge, England, pg. 1001$1005,1996$.

[15] Gobelbecker M., \& Dornhege C., "Realistic cities in simulated environments- an open street map to RoboCup Rescue converter". In $4^{\text {th }}$ Int'l Workshop on Synthetic Simulation and Robotics to Mitigate Earthquake Disaster (SRMED 2009), Graz, Austria, July 2009.

[16] Nair R., Ito T., Tambe M., \& Marsella S., "Task allocation in the rescue simulation domain: A short note", Volume 2377 of Lecture Notes in Computer Science. Springer, Berlin 751-754, 2002.

[17] Boffo F., Ferreira P. R., \& Bazzan A. L., "A comparison of algorithms for task allocation in robocup rescue", Proceedings of the 5th European workshop on multiagent systems, 537-548, 2007.

[18] Hunsberger L.,\& Grosz B., "A combinatorial auction for collaborative planning", Proceedings of the fourth international conference on multiagent systems, 2000.

[19] Beatriz L., Silvia S., \& Josep L., "Allocation in rescue operations using combinatorial auctions", Artificial Intelligence Research and Development, Vol. 100, 233-243, 2003.

[20] Chan C. K., \& Leung H. F., "Multi-auction approach for solving task allocation problem", Lecture Notes in Computer Science, Vol 4078, 
240-254, 2005.

[21] Sandholm T., "Algorithm for optimal winner determination in combinatorial auctions", Artificial Intelligence, Vol 135, 1-54, 2002.

[22] Arai K., \& Sang T. X., "Multi Agent-based Rescue Simulation for Disable Persons with the Help from Volunteers in Emergency Situations", International Journal of Research and Reviews in Computer Science, Vol. 3, No. 2, April 2012.

[23] Arai K., \& Sang T. X., "Fuzzy Genetic Algorithm for Prioritization Determination with Technique for Order Preference by Similarity to Ideal Solution", International Journal of Computer Science and Network Security, Vol. 11, No. 5, pp. 229-235, May 2011.

[24] Christensen K. M., \& Sasaki Y., "Agent-Based Emergency Evacuation Simulation with Individuals with Disabilities in the Population", Journal of Artificial Societies and Social Simulation 11(3)9, 2008.

\section{AUTHORS PROFILE}

Kohei Aarai He received BS, MS and PhD degrees in 1972, 1974 and 1982, respectively. He was with The Institute for Industrial Science and Technology of the University of Tokyo from April 1974 to December 1978 and also was with National Space Development Agency of Japan from January, 1979 to March, 1990. During from 1985 to 1987, he was with Canada Centre for Remote Sensing as a Post Doctoral Fellow of National Science and Engineering Research Council of Canada. He moved to Saga University as a Professor in Department of Information Science on April 1990. He was a councilor for the Aeronautics and Space related to the Technology Committee of the Ministry of Science and Technology during from 1998 to 2000. He was a councilor of Saga University for 2002 and 2003. He also was an executive councilor for the Remote Sensing Society of Japan for 2003 to 2005. He is an Adjunct Professor of University of Arizona, USA since 1998. He also is Vice Chairman of the Commission-A of ICSU/COSPAR since 2008. He wrote 33 books and published 500 journal papers. 